\title{
Bond Characteristics of GFRP Sheet on Strengthened Concrete Beams due to Flexural Loading
}

\author{
Rudy Djamaluddin, Mufti Amir Sultan, Rita Irmawati, and Hino Shinichi
}

\begin{abstract}
Fiber reinforced polymer (FRP) has been applied to many purposes for civil engineering structures not only for new structures but also for strengthening of the deteriorated structures. The application of FRPs in various forms such as rod, grid and sheet are widely accepted solution due to its corrosion resistance as well as high tensile strength to weight ratio. Glass composed FRP (GFRP) sheet is most commonly used due to its relatively lower cost compared to the other FRP materials. GFRP sheet is applied externally by bonding it on the concrete surface. Many studies have been done to investigate the bonding of GFRP sheet. However, it is still very rarely studies on the bonding behavior of GFRP sheet on the strengthened beams due to flexural loadings. This is important to be clarified for the wider application of GFRP sheet especially on the flexural structure such as highway bridge girders. This study presented the results of experimental investigation of the bonding behavior on the strengthened concrete beams due to flexural loadings. A series of concrete beams strengthened with GFRP sheet on extreme tension surface were prepared. Results indicated the bonding distribution along the GFRP sheet due to flexural loading tended to be non-linear. The bond stress due to flexural loading was lower than the direct shear bond stress.
\end{abstract}

Index Terms-Flexural, bond stress, strengthening, GFRP sheet.

\section{INTRODUCTION}

The development of the fiber based composite materials as well known as Fiber Reinforced Plastics (FRP) have been accepted as an alternative materials for the conventional steel reinforcement. Commonly FRP types are glass fiber reinforced plastics (GFRP), carbon fiber reinforced plastics (CFRP), aramid fiber reinforced plastics (AFRP), respectively. For the application, the FRPs have been developed in the various forms, such as rod, grid, plate and sheet. It has been applied to many purposes for civil engineering structures not only for new structures but also for strengthening of the deteriorated structures. Many techniques and method are currently developed for structural strengthening and rehabilitation. Research on the application of such materials to concrete structures is being done by many researchers in many fields. The use of fiber materials in the form of Fiber Reinforced Polymer (FRP) for application to the concrete structures offers several desirable attributes,

Manuscript received March 15, 2014; revised June 3, 2014. This work was supported financially by the Directorate General of Higher Education (DGHE) of Indonesia.

Rudy Djamaluddin, Mufti Amir Sultan, and Rita Irmawati are with the Hasanuddin University, Makassar, South Sulawesi, Indonesia (e-mail: rudy0011@hotmail.com, rita_irmaway@yahoo.co.id).

Hino Shinichi is with the Kyushu University, Fukuoka, Japan (e-mail: hino@doc.kyushu-u.ac.jp). such as resistance to corrosion, high strength, light weight, and ease of handling [1]-[3].

In the form of sheet, the FRP may be applied for strengthening of the structures by bonding it to the concrete surface. Glass fiber sheet as shown in Fig. 1 is most commonly used due to its relatively lower cost compared to the other FRP materials. The GFRP sheet is bonded to the concrete surface to have its advantages in the flexural action of the beams. GFRP sheet can be effectively used to increase the flexural strength by attaching at the extreme tension surface [3]-[6]. Therefore, the bonding of GFRP sheet to the concrete surface plays an important role in order to achieve a good mechanical action. The interaction between GFRP sheet and the concrete surface is a key factor to achieve a mechanical flexural action. Premature failure may occur when the bond stress in the GFRP exceed the bonding capacity. The prediction of the bond capacity of bonded GFRP is important to determine the flexural capacity of the beams. Bonding capacity is depend on the bonding strength of the GFRP to the concrete surface. The bonding strength may be divided into two categories which are bonding strength on the perpendicular direction of bonding area (transversal bonding strength) and bonding strength on longitudinal direction of bonding area (shear bonding strength), respectively.

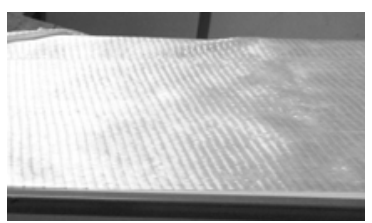

Fig. 1. Glass fiber sheet.

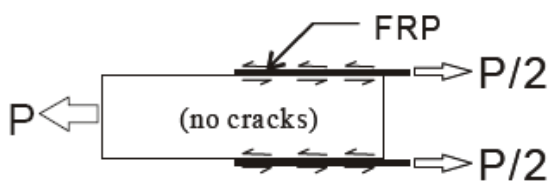

(a). Direct she ar bonding stress.

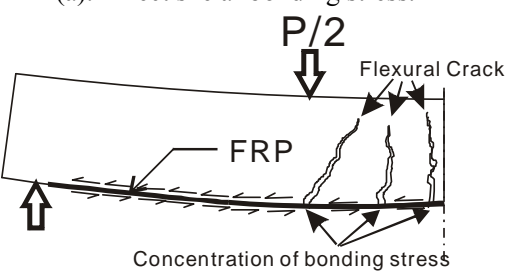

(b). Flexural bonding stress.

Fig. 2. Bonding stress of FRP sheet.

In application of FRP sheet, the shear bonding strength (hereinafter called as bonding strength) is most important. Many studies have been done to investigate the bonding strength of GFRP sheet. Dong-Uk C. et al., (2011) conducted a bond test of hybrid FRP sheet under direct tensile loading 
using double face shear tests specimens [7]. Alam M. S. et al, (2012) conducted a study on the shear-peeling bond strength under the combination of axial and shear forces using uniaxial tension specimens [8]. Mehdi T. K et al., (2011) conducted a bond test to simulate the tension zone of the beam in the cracked regions as well as in the anchorage regions based on the double face under direct tensile loading [9]. Bonding stress investigated through a direct test cannot be applied directly in designing of the flexural beams. Calibrating factors should be applied in calculating of moment capacity to make the results fit [7].

In application of FRP sheet to strengthen a concrete girder that subjected to the flexural loading, the bonding capacity of FRP sheet as well as its behavior may different with the bonding capacity under direct axial loading. In case of flexural strengthened beams, the initiation of delaminating may be induced by the opening of the flexural cracks. Fig. 2 shows the illustration of bonding stress of FRP. This results in a reduction of bond strength of FRP in the flexural beam. Hence, the bond performance of the strengthened beams depends not only on the bonding area but also on the combination of the cracks occurred on the beams. It is still very rarely studies on the bonding behavior of GFRP sheet on the strengthened beams due to flexural loadings. Further study is needed to clarify the bond behavior of GFRP sheet on the flexural concrete beams. Therefore, the objective of this study is to observe the bonding behavior of the GFRP sheet on the concrete beams under flexural loadings.

\section{Specimens AND Test Setup}

\section{A. Specimens}

A series of concrete beams were prepared for this study with parameters of the bonding area of GFRP sheet. The specimens were divided into two types, which are strengthened beams on all span (BFL) and strengthened beams on one-third span at the span center (BFH), respectively. The details of specimens are presented on the Fig. 3. The cross section of beam specimen was $100 \times 120$ $\mathrm{mm}$ with the total length of $600 \mathrm{~mm}$. All specimens were pre-cracked by a notch of $10 \mathrm{~mm}$ along the width of beams at the span center to localize the crack when loading. Un-continuous D10 steel reinforcement were applied in both side of the beam with the space of $20 \mathrm{~mm}$ between them (Fig. 3 ) to avoid concrete failure or cracks on the shear span. The concrete beams were cured for 28 days before the application of the GFRP sheet. The cylinders as well as beam specimens for rupture test were also prepared to determine the material properties of concrete. Table I presents the material properties of the concrete. Compressive strength of concrete at 28 days was $22.2 \mathrm{MPa}$ with Young of Modulus of 22.14 $\mathrm{GPa}$. The rupture strength of concrete was $3.3 \mathrm{MPa}$.

Before the application of GFRP sheet, the bottom surfaces of the beams were smoothed by a disk sander. The epoxy resin was applied on the GFRP sheet placed on the table using a soft roller to impregnate all the fibers in the resin. The epoxy resin was applied on the treated surface using a soft roller before patching of the impregnated GFRP sheet to the treated surface. The patched GFRP sheet was positioned with the application of slight pressure using a soft roller. The beams were then cured again for 3 days to allow the hardening of resin. Table II shows the material properties of the manufacturer data sheet of glass fibers and GFRP, and Table III shows the manufacturer data sheet of epoxy resin, respectively. The GFRP used in this study was composed by E-Glass and epoxy resin. The GFRP has tensile strength of $575 \mathrm{MPa}$ with elastic modulus of $26.1 \mathrm{GPa}$.

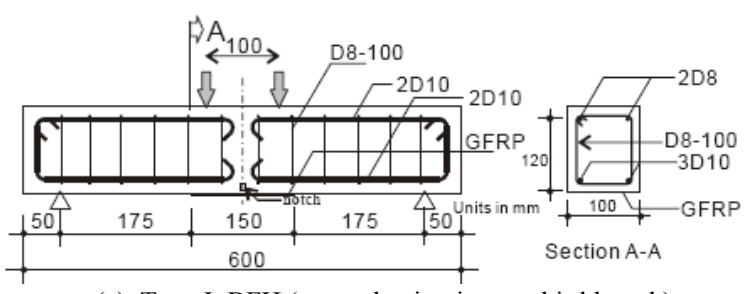

(a). Type I: BFH (strengthening in one-third length).

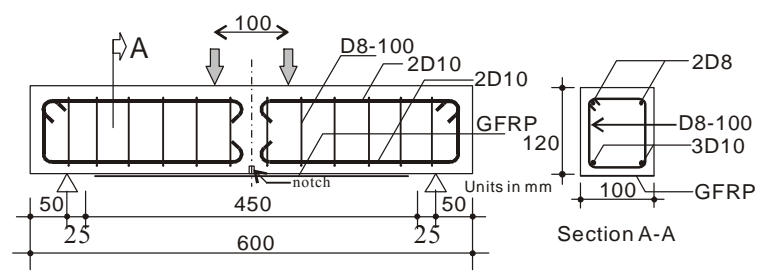

(b). Type II: BFL (strengthening in full length). Fig. 3. Detail of Specimens

TABLE I: MATERIAL PROPERTIES OF CONCRETE

\begin{tabular}{lc}
\hline \multicolumn{1}{c}{ Items } & Properties \\
\hline Compressive Strength $(\mathrm{MPa})$ & 22.2 \\
\hline Modulus Young $(\mathrm{GPa})$ & 22.14 \\
\hline Rupture Modulus fr $(\mathrm{MPa})$ & 3.3 \\
\hline
\end{tabular}

TABLE II: MATERIAL PROPERTIES OF GLASS FIBER AND GFRP

\begin{tabular}{lcc}
\hline \multicolumn{1}{c}{ Items } & Glass Fiber & GFRP \\
\hline Type & SEH-51A & - \\
\hline Tensile Strength (MPa) & 3240 & 575 \\
\hline Modulus Young (GPa) & 72.4 & 26.1 \\
\hline Laminate Thickness (mm) & 0.36 & 1.3 \\
\hline
\end{tabular}

TABLE III: MATERIAL PROPERTIES OF EPOXY RESIN

\begin{tabular}{lc}
\hline \multicolumn{1}{c}{ Items } & Properties \\
\hline Tensile Strength $(\mathrm{MPa})$ & 72.4 \\
\hline Modulus Young $(\mathrm{GPa})$ & 3.18 \\
\hline Bonding Strength* $(\mathrm{MPa})$ & 2.12 \\
\hline
\end{tabular}

* Based on the ter
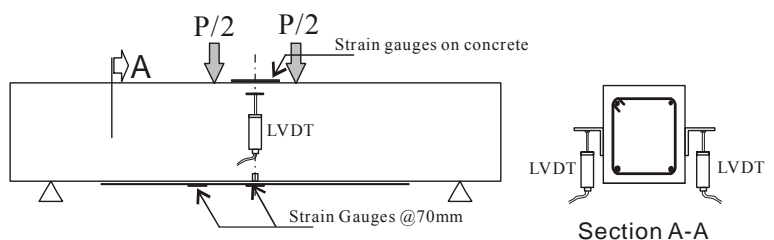

Fig. 4. Test setup.

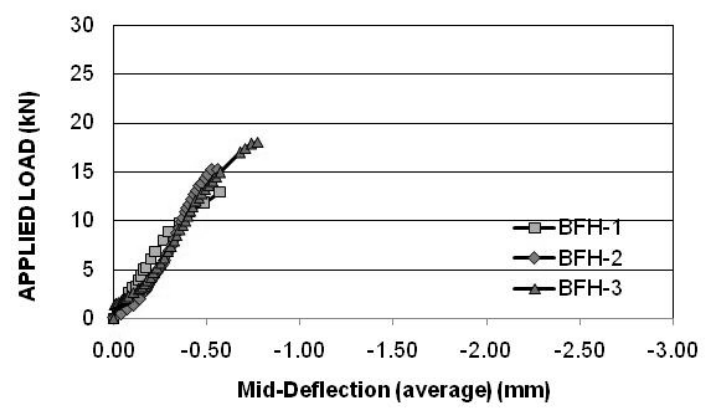

Fig. 5. Load-deflection curve of specimen BFH. 


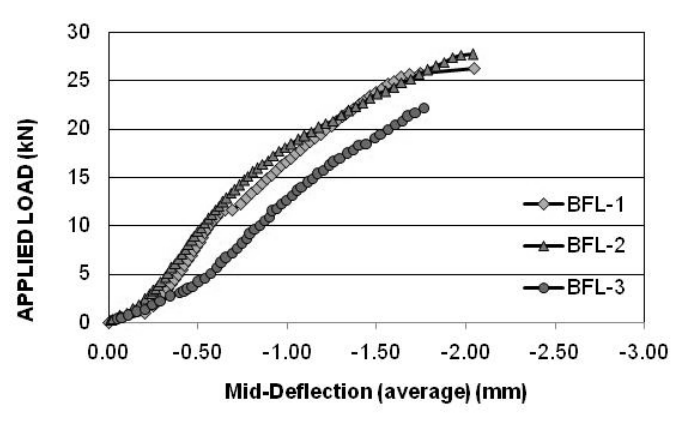

Fig. 6. Load-deflection curve of specimen BFL.

\section{B. Test Setup}

The beam specimens were tested under simple supported beams subjected to two point load using a universal testing machine, as shown in Fig. 4. Each specimen was instrumented by strain gauges on concrete surface at extreme compression surface and on the GFRP sheet, respectively. The deflection and loading were measured using LVDTs and a load cell. The load was applied gradually with constant rate of $5 \mathrm{kN}$ per minutes up to failure. All instrumentation was connected to a computer based data logger for data recording.

\section{RESUlTS AND DisCUSSION}

\section{A. Flexural Capacities}

Fig. 5 and Fig. 6 show the load-deflection relationship of the specimens BHL and BFL, respectively. It can be observed that both type has similar flexural behavior up to failure. Initially, the specimens were uncracked beams. The concrete section resisted both compression and tension stresses. At this stage the GFRP sheet resisted only small portion of tension forces.

Further loading caused a cracks occurred on the notch at the span center. Once the concrete cracks, the tension stresses was resisted only by GFRP sheet. It should be noted here, that all beams did not have a steel tensile reinforcement. Higher elastic modulus of the GFRP sheet caused the stiffness of the beams slightly increased. The single cracks continued to propagate upward to the compression zone. As the results, the compression stress of the concrete increased to achieve the equilibrium with the tensile stress of the GFRP sheet. Mechanics interaction between tension force at the GFRP and compression force at the concrete is just influenced by the bonding stress between GFRP sheet to the concrete surface. Therefore, increasing of flexural moment resulted the increasing of bonding stress of GFRP sheet. The beams failed when the bonding stress achieved its ultimate bonding capacity. On the flexural beams, the rupture bonding stress of the GFRP may be influenced also by the flexural cracking.

Table IV present the first cracking moment and the maximum moment capacity of the specimens. The maximum moment capacity of the BFH beams was achieved when the applied load equal to approximately $15 \mathrm{kN}$, while on the BFL specimens was $25 \mathrm{kN}$, respectively. The first crack moment was not influenced significantly by the bonding length of the GFRP sheet. This indicated by the first cracking moment of beams strengthened with $150 \mathrm{~mm}$ of GFRP sheet (BFH) is approximately same to the first cracking moment of beams strengthened with $450 \mathrm{~mm}$ of GFRP sheet (BFL). However, the bonding length of GFRP sheet significantly influenced the maximum moment capacity of the beams. Maximum capacity of the beams BFL is approximately twice than the moment capacity of the beams BFH.

TABLE IV: SUMMARY OF FIRST CRACKING MOMENT AND MAXIMUM

\begin{tabular}{lccc}
\multicolumn{4}{c}{ MOMENT } \\
\hline Specimen & $\begin{array}{c}\text { First crack } \\
\text { moment } \\
(\mathrm{kN} . \mathrm{m})\end{array}$ & $\begin{array}{c}\text { Maximum } \\
\text { moment } \\
(\mathrm{kN} . \mathrm{m})\end{array}$ & $\begin{array}{c}\text { Deflection at } \\
\text { Mmax } \\
(\mathrm{mm})\end{array}$ \\
\hline BFH-1 & 0.426 & 1.294 & 0.573 \\
\hline BFH-2 & 0.344 & 1.518 & 0.560 \\
\hline BFH-3 & 0.416 & 1.803 & 0.770 \\
\hline BFL-1 & 0.394 & 2.619 & 2.040 \\
\hline BFL-2 & 0.421 & 2.771 & 2.040 \\
\hline BFL-3 & 0.301 & 2.215 & 1.760 \\
\hline
\end{tabular}

\section{B. Response of Concrete and GFRP Sheet}

The flexural action of the beams is the couple action between the compressive stress and the tensile stress of the beams. Further loading after first cracks, the couple action was developed by the compression force on the compressive concrete and the tension force on the tensile GFRP sheet. Fig. 7 present the compressive strain of the concrete recorded from the strain gauges that was attached on the top of beams at the span center while Fig. 8 shows the tensile strain of the GFRP sheet recorded from the strain gauges that was patched on the span center, respectively. The increasing of the concrete strain was followed by the increasing of the strain of GFRP. On the specimen BFH, one of the beam specimen (BFH-3) showed a different behavior to the other two specimens. This may be caused by the human error in patching the GFRP sheet during the specimen preparation. For the other two specimens of BFH, the strain propagated in the same manner up to failure. The maximum strain on the concrete and the GFRP sheet were approximately $350 \mu$ and $850 \mu$, respectively. This indicated that the zero strain was above the center of gravity of the beam cross section. Similar to the specimens BFL, both strain of concrete and GFRP sheet increased by increasing of the applied load. The maximum strain on the concrete and the GFRP sheet were approximately $1250 \mu$ and $3000 \mu$, respectively.

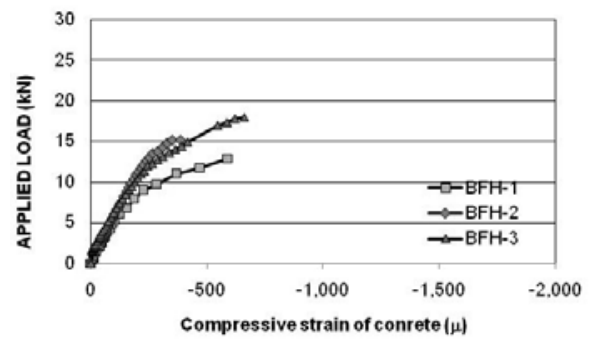

(a) Specimens BFH.

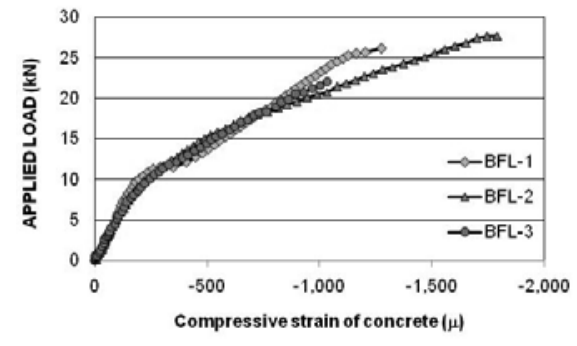

(b) Specimen BFL/

Fig. 7. Compressive strain of concrete. 


\section{Bond Strength Evaluation}

In case of the flexural beams, the bonding stress is influenced by tensile stress of the GFRP sheet attached at the extreme tension surface. In order to develop equilibrium of internal forces, then the compression is resisted by concrete and the tension is resisted by GFRP sheet. Fig. 9 illustrates the flexural strain and stress diagram as well as the illustration of the flexural bonding stress on GFRP sheet. Due to the relatively still small value on the concrete strain, the elastic relationship between strain and stress may be assumed. The moment capacity $M_{n}$ of the flexural beam was developed by the couple action between compression force $C_{c}$ and tension force on GFRP sheet $T_{f}$ with the arm $z$ that may be expressed as on (1).

$$
M_{n}=T_{f} \times z=C \times z
$$

where:

$$
z=\left(h-\frac{1}{3} a\right)
$$

and

$$
a=\frac{\varepsilon_{c} h}{\varepsilon_{f}+\varepsilon_{c}}
$$

where, $\varepsilon_{c}$ is the experimental concrete strain, $h$ is the beam height, and $\varepsilon_{f}$ is the experimental strain on the GFRP

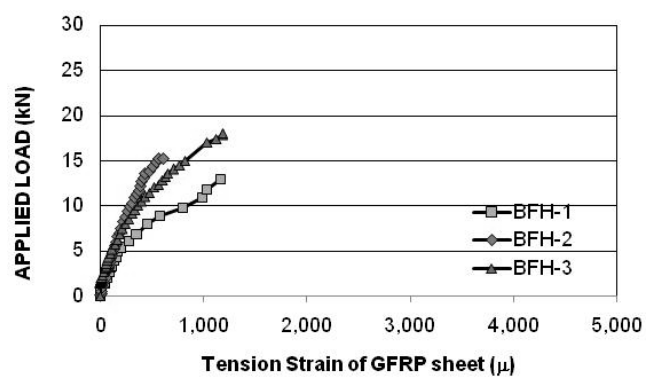

(a) Specimens BFH.

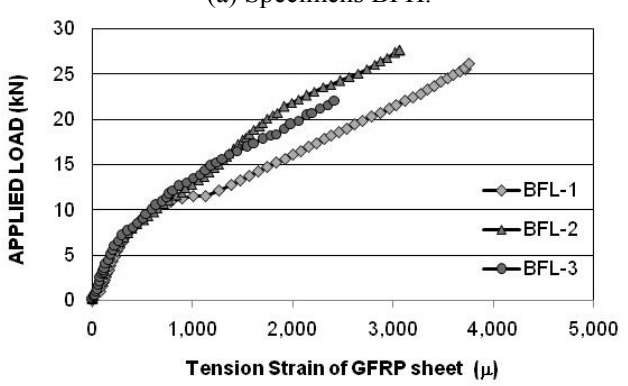

(b) Specimen BFL

Fig. 8. Tension strain of GFRP sheet.
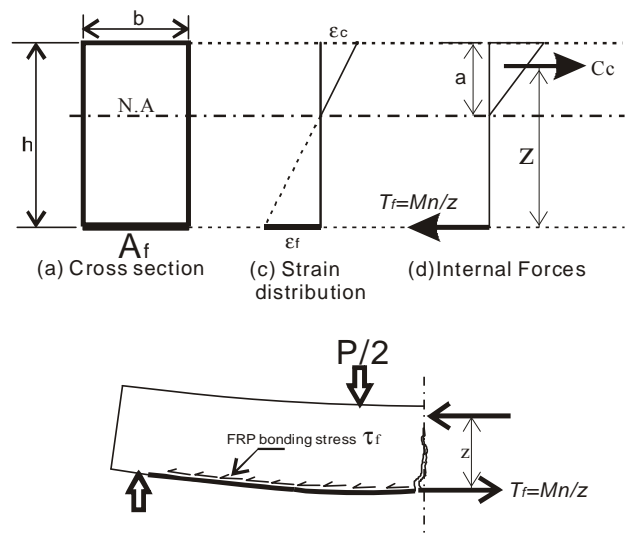

(e)Bonding stress due to Flexural Tensile forces

Fig. 9. Flexural bonding stress.
The depth of the compression stress diagram $a$ as on Fig. 7 may be estimated by substituting the experimental strain of concrete $\varepsilon_{c}$ and the strain of GFRP sheet $\varepsilon_{f}$ to (3). Then, the tensile force of GFRP sheet $T_{f}$ may be estimated by (4).

$$
T_{f}=\frac{M_{n}}{\left(h-\frac{1}{3} a\right)}
$$

The interaction of the GFRP sheet with the concrete was only due to the effect of bonding between GFRP sheet and the concrete surface at the extreme tension surface. The average bonding stress on the GFRP sheet may be simply expressed by (5).

$$
\tau_{f}=\frac{T_{f}}{A_{b f}}
$$

where, $T_{f}$ is tension force on GFRP sheet and $A_{b f}$ is the bonding area of the GFRP sheet. Table $\mathrm{V}$ shows the calculation of the average bonding stress on specimens BHL and BFL respectively. Results indicated that the increasing of the bonding length reduced the average bonding stress on the GFRP sheet. The average bonding stress on the specimen BHL was $2.40 \mathrm{MPa}$, while bonding stress of the specimen BFL was $1.28 \mathrm{MPa}$. The bonding stress mentioned here is the shear bonding stress due to flexural loading. Manufacturer has conducted both transversal bonding test and shear bonding test as illustrated in Fig. 10 to clarify the bonding strength of GFRP used in this study. It was found that the transversal bonding strength was $3.11 \mathrm{MPa}$, while the shear bonding strength was $4.08 \mathrm{MPa}$, respectively [10], [11]. Compared to the shear bond strength $\tau$ bf based on shear direct test (ASTM C 482:81(1996) conducted by the manufacturer, the average bond stress due to flexural loading conducted in this study was much lower. This indicated that the attention should be taken in determine the bonding stress in estimating the flexural capacity of the concrete beams strengthened using GFRP sheet.

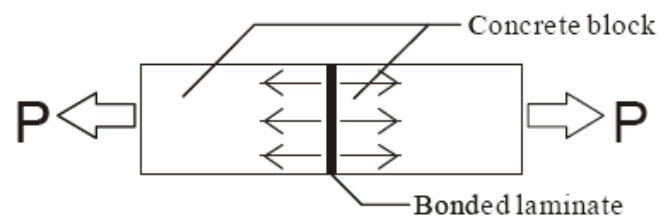

(a). Transversal bonding stress.

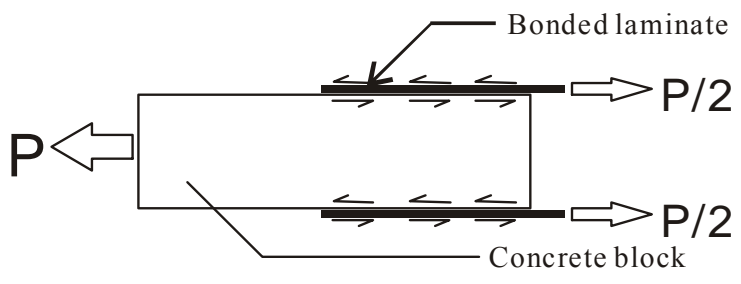

(b). Shear bonding stress.

Fig. 10. Illustration of bonding test of manufacturer.

\section{Strain Distribution}

Fig. 11 shows the tension strain distribution from the span center to the far end of the GFRP sheet that represents the bond stress distribution. The results were based on the strain gauges patch on the span center (zero $\mathrm{mm}$ ) and $75 \mathrm{~mm}$ far 
away from the span center. The strain at both gauges increased as the load increased. At lower load, the distribution tended to be linear form maximum at the span center to zero at the end. Increasing the applied load, the distribution pattern gradually changes to be non-linear. Due to the increase in load and corresponding crack width, the strain on the next strain gauges from the center increased. As it can be observed that the strain at the maximum load limited by delaminating was influenced also by the bond length of GFRP sheet. On the specimen BFH the maximum strain on GFRP on the span center was $1100 \mu$ decreased to almost zero on the strain gauges patched $10 \mathrm{~mm}$ from the end of GFRP sheet. While, on the specimen BFL the maximum strain at the span center was $3100 \mu$. However, the strain at 75 $\mathrm{mm}$ from the span center increased to be approximately 3900 $\mu$ and then decrease to zero at the end of the GFRP sheet. The increasing of the strain at that point started when the load was increased further above $20 \mathrm{kN}$.

\begin{tabular}{lcccc}
\multicolumn{4}{c}{ TABLE V: Estimated AveraGe BOnding STRENGTH } \\
\cline { 1 - 4 } Specimen & $T f(\mathrm{kN})$ & $A b f(\mathrm{~mm} 2)$ & $\begin{array}{c}f \\
(\mathrm{MPa})\end{array}$ & $\begin{array}{c}b f^{*} \\
(\mathrm{MPa})\end{array}$ \\
\hline BHL & 17.99 & 7500 & 2.40 & \multirow{2}{*}{4.08} \\
\hline BFL & 28.83 & 22500 & 1.28 & \\
\hline
\end{tabular}

* Based on the shear bond test of manufacturer

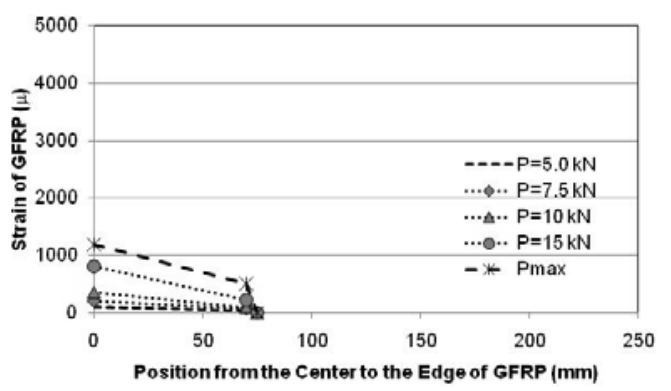

(a) Specimens BFH.

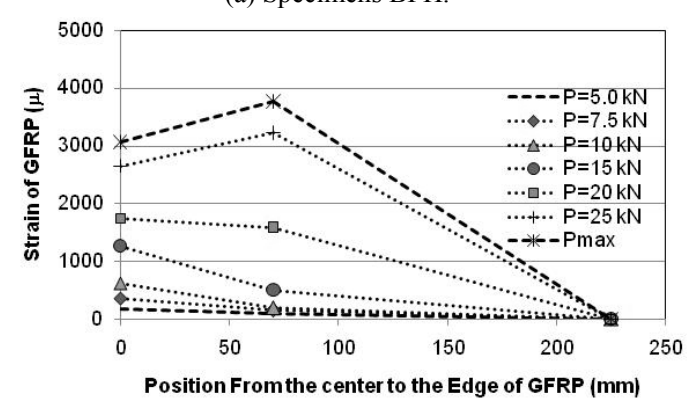

(b) Specimen BFL.

Fig. 11. Strain distribution along the GFRP sheet.

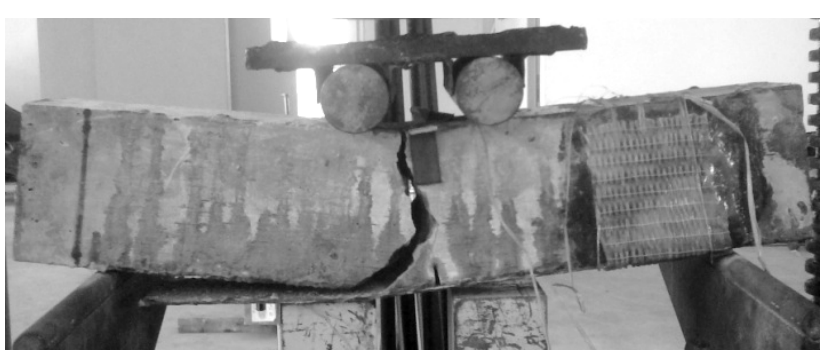

Fig. 12. Photograph of the failed specimens.

\section{E. Failure Mode}

Fig. 12 presents the photograph of the failed specimens. The failure was initiated by the flexural cracks occurred at the span center within zero moment zone. Increasing of load caused the increasing of the bonding stress on the crack edge. Once the bonding stress exceeded the bonding capacity, then the beam failed due to delaminating of the GFRP sheet. The delaminating started from the crack edge simultaneously to the end of the GFRP sheet. The maximum strain on GFRP at the maximum load was still approximately $4000 \mu$ which was still smaller than the rupture strain of the material.

\section{CONCLUSIONS}

The bond stress between the GFRP sheet and concrete on the flexural beam is relatively lower than direct shear bond test. Based on the experimental study, the following may be concluded:

1)Bonding length of GFRP sheet was significantly influenced the maximum moment capacity of the beams. Maximum capacity of the beams BFL is approximately twice than the moment capacity of the beams BFH.

2) The increasing of the bonding length reduced the average bonding stress on the GFRP sheet. The average bonding stress on the specimen strengthened by one-third at span center was $2.40 \mathrm{MPa}$, while bonding stress of the specimen strengthened on full-length of span was 1.28 $\mathrm{MPa}$.

3) Average bond stress due to flexural loading conducted in this study was lower than the bond strength based on shear direct test.

4) The strain at the maximum load limited by delaminating was influenced also by the bond length of GFRP sheet. On the specimen strengthened by one-third at span center, the maximum strain on GFRP on the span center was $1100 \mu$ decreased to almost zero on the strain gauges patched $10 \mathrm{~mm}$ from the end of GFRP sheet. Specimen strengthened on full-length of span, the maximum strain at the span center was $3100 \mu$.

\section{ACKNOWLEDGMENT}

The study was a part of research scheme which was supported by the Directorate Higher Education of the Republic of Indonesia (DGHI) under the research grant of International Research Cooperation. The authors would like also to acknowledge the member of the Civil Department of Hasanuddin University for them valuable supports in conducting the study. Acknowledge is also expressed to the Laboratory of the bridge and structural engineering of Kyushu University for them kind cooperation and advices. The acknowledgement is extended also to PT. Fyfe Fibrwrap Indonesia for them valuable support in technical assistance during the application of GFRP Sheet.

\section{REFERENCES}

[1] Y. S. Shin and C. Lee, "Flexural behavior of reinforced concrete beams strengthened with carbon fiber -reinforced laminates at different levels of sustaining loads," ACI Structural Journal, vol. 100, no. 2, pp.231-239, Mar-Apr 2003

[2] J. G. Teng, J. F. Chen, S. T. Smith, and L. Lam, FRP-Strengthened RC Structures, West Succex, UK: John Wiley and Sons, no. 266, pp. 2003.

[3] D. Rudy, M. A. Abdul, and E. S. Akristin, "Application of GFRP sheet for strengthening of yielded reinforced concrete beams," in Proc. the 
6th Civil Engineering Conference in Asia Region, pp.TS10-9 TS10-16, Jakarta, 2013.

[4] H. Rahimi and A. Hutchinson, "Concrete beams strengthened with externally bonded FRP plates," Journal of Composites for Construction, ASCE, vol. 5, no. 1. pp. 44-55, 2001.

[5] P. Balaguru, A. Nanni, and J. Guancaspro, FRP Composites for Reinforced and Prestressed Concrete Structures: A Guide to Fundamentals and Design for Repair and Retrofit, Taylor \& Francis, 2009.

[6] L. D. Lorenzis, B. Miller, and A. Nanni, "Bond of fiber-reinforced polymer laminates to concrete," ACI Material Journal, vol. 98, no. 3, May-June 2001, pp. 256-264, 2001.

[7] D. U. Choi, T. H. K. Kang, S. S. Ha, K. H. Kim, and W. Kim, "Flexural and bond behavior of concrete beam strengthened with hybrid carbon-glass fiber reinforced polymer sheet," ACI Struct. J., vol. 108 , no. 1 , pp. 90-98, 2011.

[8] M. S. Alam, T. Kanakubo, and Yasojima, "Shear-peeling bond strength between continuous fiber sheet and concrete," ACI Structural Journal, vol. 109, no. 1, pp. 75-82, Jan.-Feb. 2012

[9] T. K. Mehdi and J. B. Chris, "Fiber-reinforced polymer bond test in presence of steel and cracks," ACI Structural Journal, vol. 108, no. 6, pp. 735-744, Nov.-Dec. 2011.

[10] P. T. F. Fibrwrap, "Test Report for bonding strength Tyfp S + SHE-51,” 2013.
[11] Fibrwrap Construction Pte.Ltd, "Test Report for testing of shear strength for SEH55H glass fiber," 2003.

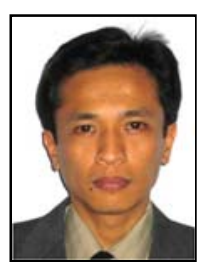

Rudy Djamaluddin is an associate professor of the Department of Civil Engineering at the Hasanuddin University, Makassar-South Sulawesi of Indonesia. He was born on November 8, 1970 in Gowa-Indonesia. He received his BS from Hasanuddin University of Indonesia; $\mathrm{MS}$ and $\mathrm{PhD}$ from Kyushu University of Japan. His research interest includes the use of fiber reinforced composites for structural strengthening and rehabilitation. He is a member of some professional organizations such as: Indonesian Structural Engineer Association (HAKI) and Indonesian Engineer Associations (PII). He has been awarded by some research grant such as: Research grant from Japan Society for Promotions of Science (JSPS) on 2005 and conducted a Post Doctoral Research at Laboratory of Bridge and Structural Engineering of Kyushu University from 2003 to 2005, research grant from the Ministry of the Indonesian Higher Education on 2012, research grant for Short Term Research on Laboratory of Bridge and Structural Engineering of Kyushu University for six months on 2012, research Grant for laboratory based research from Hasanuddin University on 2013. 